\title{
SOROEPIDEMIOLOGIA DE Rhodococcus equi EM EQUINOS DA REGIÃO DE BAGÉ, RS, PELO TESTE DE INIBIÇÃO DA HEMÓLISE SINÉRGICA ${ }^{1}$
}

\author{
Andrea Lazzari ${ }^{2}$, Agueda Castagna de Vargas ${ }^{3}$, Valéria Dutra ${ }^{4}$, Andreia Foletto \\ Pedrozo $^{5}$, Lucia Helena Niederauer Weiss ${ }^{2}$ e Gregori Luis Ferreira ${ }^{6}$
}

\begin{abstract}
Lazzari A., Vargas A.C., Dutra V., Pedrozo A.F., Weiss L.H.N. \& Ferreira G.L. 1997. [Seroepidemiology on Rhodococcus equi in horses from Bagé county, RS, by using the synergistic hemolysis inhibition test.] Soroepidemiologia de Rhodococcus equi em equinos da região de Bagé, RS, pelo teste de Inibição da Hemólise Sinérgica. Pesquisa Veterinária Brasileira 17(3/4):117-122. Depto Medicina Veterinária Preventiva, Universidade Federal de Santa Maria, 97119-900 Santa Maria, RS, Brazil.

Rhodococcus equi seroepidemiological studies were conducted. Sera used were collected from 290 apparently clinically normal mares and foals. The samples originated from 6 horsebreeding farms, located in the county of Bagé, Rio Grande do Sul, Brazil, which had different histories of Rhodococcus equi infections. To correlate the serological results with the presence of the agent in the intestine 123 fecal samples were collected. The synergistic hemolysis inhibition test was used. The test detects antibody against the "equi factor". Neutralizing antibodies against the equi factor were verified in $87.93 \%(255 / 290)$ of the animales tested. The geometric mean titer (GMT) of antibodies was higher in the foals when comparad with the mares. The serological results had a correlation with the isolation of $R$. equi in the feces. The rate of $R$. equi isolation and GMT titers was higher at the horse-breeding farm where clinical cases were registered. Further studies need to be done to establish the relation among the importance of serological titers and disease detection.
\end{abstract}

INDEX TERMS: Horses, serology, synergistic hemolysis inhibition.

SINOPSE.- Com o objetivo de avaliar a situação soroepidemiológica da infecção por Rhodococcus equi na região de Bagé, RS, foram testadas 290 amostras de soro sanguíneo de éguas e potros aparentemente sadios, obtidos de 6 haras com dife-

\footnotetext{
${ }^{1}$ Aceito para publicação em 14 de julho de 1997.

Trabalho extraído da dissertação de mestrado do primeiro autor, apresentada ao curso de Pós-Graduação em Medicina Veterinária, Universidade Federal de Santa Maria, Rio Grande do Sul.

2 Médico Veterinário, Depto Medicina Veterinária Preventiva, Setor de Bacteriologia, Universidade Federal de Santa Maria (UFSM), 97119-900 Santa Maria, RS.

${ }^{3}$ Depto Medicina Veterinária Preventiva, Setor de Bacteriologia. Fax (055) 220 8695; Email: Agueda.@.CCR.UFSM.BR. Autor para correspondência.

${ }^{4}$ Aluno do curso de Pós-Graduação (Área de Medicina Veterinária Preventiva) da UFSM.

${ }^{5}$ Acadêmico do curso de Medicina Veterinária da UFSM; bolsista do CNPq.

${ }^{6}$ Acadêmico do curso de Medicina Veterinária da UFSM; bolsista da FAPERGS.
}

rentes histórias de rodococose. Para relacionar o resultado sorológico com a presença deste agente bacteriano no trato intestinal destes animais, foram coletadas 123 amostras de fezes. O teste sorológico utilizado foi a inibição da hemólise sinérgica (IHS) que detecta anticorpos neutralizantes contra o "fator equi". Um percentual de 87,93\% (255/290) dos animais amostrados apresentaram estes anticorpos. 0 título médio geométrico (GMT) destes anticorpos foi mais elevado nos potros do que nas éguas. A soropositividade destes equinos ao teste sorológico teve correlação com o isolamento do $R$. equi nas fezes dos respectivos animais. A maior taxa de isolamento de $R$. equi das fezes dos equinos e o maior GMT, ocorreu no único haras com casos clínicos recentes de enfermidade causada por esta bactéria. No entanto, todos os animais deste e dos demais haras, encontravam-se aparentemente sadios, sendo necessário, estabelecer em trabalho futuro, a possível relação entre títulos de anticorpos e sua importância na detecção da enfermidade.

TERMOS DE INDEXAÇÃO: Equinos, sorologia, inibição da hemólise sinérgica. 


\section{INTRODUÇÃO}

Rhodococcus equi é um cocobacilo gram positivo capsulado (Bisping \& Amtsberg 1988, Carter \& Cole 1990, Quinn et al. 1994) que pode ser encontrado no trato gastrointestinal de equinos (Takai et al. 1987, Woolcock et al. 1987). Pode causar em potros de até 6 meses de idade uma broncopneumonia piogranulomatosa, enterite ulcerativa e linfoadenite mesentérica (Prescott \& Hoffman 1993, Takai et al. 1995).

Segundo Prescott (1991) $R$. equi encontra-se distribuído mundialmente, sendo relatado como responsável por mais de 3\% das mortes em potros, podendo alcançar taxas de mortalidade de $80 \%$ (Hillidge 1986). O pico de incidência da doença parece coincidir com o período em que os anticorpos adquiridos passivamente começam a desaparecer (Prescott 1987).

Após várias tentativas para detecção de anticorpos contra $R$. equi, foi descoberto que todas as cepas desta bactéria produzem uma exosubstância denominada "fator equi", composta por duas enzimas, a colesterol oxidase e a fosfolipase C (Prescott et al. 1982). Segundo Skalka \& Svastová (1984/ $85)$, a produção "in vitro" do "fator equii" é uma importante característica desta bactéria, e apesar das diferenças na parede celular ou sorotipo capsular, a similaridade antigênica das enzimas possibilita sua utilização como antígeno.

Os testes desenvolvidos e utilizados para a detecção de anticorpos contra o "fator equi" são a imunodifusão em gel de ágar (Nakazawa 1980, Nakazawa et al. 1987, Sweeney \& Wilkins 1992, Finger 1996); teste de inibição da hemólise sinérgica (IHS) (Prescott et al. 1984a) e a imunodifusão radial enzimática (Takai et al. 1990). O teste de IHS foi desenvolvido a partir da descoberta que o "fator equi" aumenta a atividade hemolítica de outras espécies bacterianas. Segundo Yager (1987), esta exosubstância age sinergicamente com toxinas produzidas por Corynebacterium pseudotuberculosis, Staphylococcus aureus e Listeria monocytogenes para causar completa hemólise de eritrócitos de mamíferos. Skalka \& Svastová $(1984 / 85)$ descobriram que os anticorpos produzidos pelos equinos em resposta ao "fator equi" neutralizam a hemólise de eritrócitos previamente sensibilizados por bactérias que agem sinergicamente com $R$. equi. Gaskin et al. (1990) comparando o teste de imunodifusão em gel de ágar (IDGA) com o teste de IHS, concluíram que o segundo apresenta maior sensibilidade, quantificando os anticorpos, no entanto de padronização e realização mais laboriosa.

Estudos sorológicos realizados em vários países indicam que $R$. equi está amplamente distribuído na população equina (Nakazawa 1980, Madigan et al. 1991, Sanada et al. 1992, Becu 1994) sendo encontrado inclusive em propriedades sem ocorrência da doença (Skalka 1987). No Brasil existem poucas publicações sobre estudos soroepidemiológicos, entre eles, dados publicados por Lazzari et al. (1996) no estado do Paraná e na região sudoeste do estado do Rio Grande do Sul e Finger (1996) nas regiões metropolitana e noroeste deste mesmo estado.

Os testes sorológicos, associados a um monitoramento do processo da infecção, contribuem para um diagnóstico precoce desta enfermidade (Skalka 1987), sendo que a IHS é utilizada também na determinação do título de anticorpos em equinos doadores de plasma hiperimune. $O$ objetivo deste trabalho foi avaliar a situação sorológica de equinos nos haras em estudo, bem como fornecer dados epidemiológicos desta infecção na região sudoeste do estado do Rio Grande do Sul.

\section{MATERIAL E MÉTODOS}

Animais de experimentação

Os equinos utilizados eram pertencentes a seis haras do município de Bagé, estado do Rio Grande do Sul, Brasil. O material foi coletado de éguas e potros com idade entre 2 dias e 5 meses de vida. Nenhum dos animais amostrados foi vacinado ou recebeu plasma hiperimune contra $R$. equi. Somente um haras, o de número 2 , apresentou casos clínicos recentes causados por $R$. equi, sendo considerado uma propriedade com ocorrência endêmica da infecção. Os Haras 1, 4 e 6 possuiam registros de casos que ocorreram a alguns anos, e os animais dos Haras 3 e 5 nunca foram acometidos clinicamente.

Soro sanguíneo.

Foram coletadas 290 amostras, onde:

$\begin{array}{lll}\text { Potros } & & \text { Éguas } \\ \text { Haras } 1 & 29 & 52 \\ \text { Haras 2 } & 07 & 09 \\ \text { Haras 3 } & 16 & 32 \\ \text { Haras 4 } & 31 & 35 \\ \text { Haras 5 } & 08 & 14 \\ \text { Haras 6 } & 23 & 34\end{array}$

A coleta foi realizada através da punção da veia jugular com tubos de ensaio contendo vácuo. Após a retração do coágulo as amostras de soro foram estocadas a $-18^{\circ} \mathrm{C}$ até a execução do teste.

Amostras de fezes. Foram coletadas 123 amostras de fezes diretamente da ampola retal ou da porção superior do bolo fecal recém eliminado de 68 éguas e 75 potros. As amostras foram acondicionadas em sacos plásticos limpos e refrigeradas até a chegada ao laboratório, sendo processadas em no máximo 24h após a coleta.

Inibição da Hemólise Sinérgica (IHS)

Extração da toxina de Corynebacterium pseudotuberculosis. A toxina (fosfolipase D) foi extraída segundo técnica descrita por Prescott et al. (1984a). A cepa utilizada foi obtida do Centro de Pesquisa Veterinária Desidério Finamor (CPVDF).

$O$ meio base utilizado para padronização dos reagentes e realização do teste foi o Tryptic Soy Agar $\left(\operatorname{TSA}^{7}\right)$ acrescido de $0,1 \%$ de azida sódica ${ }^{8}$. 0 meio foi distribuído em alíquotas de $30 \mathrm{ml}$, autoclavado e quando utilizado, mantido em uma temperatura de aproximadamente $50^{\circ} \mathrm{C}$. Uma quantidade de $0,003 \mathrm{~g}$ da toxina liofilizada de Corynebacterium pseudotuberculosis, diluídas em $2 \mathrm{ml}$ de PBS $(\mathrm{pH} 7,0)$ foram utilizadas para sensibilizar eritrócitos de ovino previamente lavados (3 vezes) com salina estéril $(0,85 \%)$. A concentração de eritrócitos adicionados foi de 3\% do volume total do meio base utilizado para cada placa de Petri de $135 \times 15 \mathrm{~mm}$. Estas placas sensibilizadas permaneciam durante 24 horas a temperatura ambiente antes de serem utilizadas.

\footnotetext{
${ }^{7}$ DIFCO - Interlab Distribuidora de Produtos Científicos S.A., São Paulo, SP.

${ }^{8}$ SIGMA - Pró-Análise Química e Diagnóstico Ltda, Porto Alegre, RS.
} 
Produção do "fator equi". As etapas para produção do "fator equi" seguiram descrição de Prescott et al. (1984a), com algumas modificações. O isolado de $R$. equi utilizado (SB 96/93), mantido liofilizado, foi obtido de um abscesso da cavidade abdominal de um potro. Foi definido como uma unidade do "fator equi", a maior diluição do mesmo que, após um período de incubação de 3 dias à $37^{\circ} \mathrm{C}$ sobre uma placa de meio base contendo eritrócitos sensibilizados com a toxina de $C$. pseudotuberculosis, produziu uma zona de hemólise de $1-3 \mathrm{~mm}$ ao redor do disco absorvente saturado.

Controle negativo. Soro sanguíneo de um potro recém nascido antes de mamar o colostro. Este animal pertencia a um haras de Bagé, estado do Rio Grande do Sul.

Controle positivo. Foi utilizado soro hiperimune produzido segundo descrição de Skalka \& Svastová (1984/85) com algumas modificações. Os anticorpos foram obtidos à partir de aplicações semanais do "fator equi" em coelhos adultos. A aplicação do antígeno foi subcutânea na dose de $1 \mathrm{ml}$, num total de 7 inoculações. A partir da $3^{\mathrm{a}}$ aplicação do antígeno, coletou-se sangue por punção cardíaca para controle da produção dos anticorpos através do teste de inibição da hemólise sinérgica. Padronizou-se como uma unidade de anticorpo, a diluição mais alta de soro hiperimune, que misturado com uma unidade do "fator equi" neutralizou a zona de hemólise em torno do disco absorvente saturado após 3 dias de incubação à $37^{\circ} \mathrm{C}$ sobre uma placa de meio base contendo eritrócitos sensibilizados com a toxina de $C$. pseudotuberculosis. A diluição utilizada deste soro foi de 1:8.

Em cada placa de meio base contendo eritrócitos sensibilizados com a toxina de $C$. pseudotuberculosis foram colocados os seguintes controles: a) um disco embebido em uma unidade do "fator equi" (antígeno); b) um disco com uma unidade de soro controle positivo + uma unidade do antígeno e c) um disco com uma unidade do antígeno + mesma quantidade do controle negativo. Todas estas alíquotas foram distribuídas em placas de microdiluição com pipeta monocanal ${ }^{9}$.

Inicialmente foram analisadas as 290 amostras de soro sem diluir (puro), onde, distribuiu-se em placas de microdiluição, 20 microlitros de uma unidade de "fator equi" e a mesma quantidade do soro a ser testado.

Os controles e os soros a serem testados, depois de agitados durante 60 minutos a temperatura ambiente, embeberam discos absorventes estéreis de $6,35 \mathrm{~mm}$ de diâmetro ${ }^{10}{ }^{1}$ por 10 segundos, sendo posteriormente colocados sobre a placa previamente sensibilizada de IHS, observando-se uma distância mínima de $25 \mathrm{~mm}$ entre os mesmos. As placas foram incubadas à $37^{\circ} \mathrm{C}$ durante 3 dias, quando então realizava-se a leitura do teste. Os soros positivos ao teste de IHS eram diluídos com $\mathrm{PBS}(\mathrm{pH} 7,2)$ na razão 2 , à partir da diluição 1:2 e testados até a determinação do título.

Os soros dos equinos (éguas e potros), antes de serem submetidos à técnica de inibição da hemólise sinérgica, foram testados para a deteç̧ão de toxicidade sobre uma placa de eritrócitos sensibilizados.

Leitura:

- Negativo: Presença de um halo completo de hemólise ao redor do disco.

- Positivo: Ausência do halo de hemólise ao redor do disco.

- Título de anticorpo: A maior diluição do soro sanguíneo, que após um período de 3 dias nas condições acima descritas, inibiu a hemólise ao redor do disco absorvente.

\footnotetext{
${ }^{9}$ Eppendorf Geratebau-Nethler Postfach 650670, 2000 Hamburg 65 Germany.

${ }^{10}$ CEFAR - Promicro Comércio de Produtos Hospitalares Ltda, São Paulo, SP.
}

Isolamento e identificação de $R$. equi em amostras de fezes

As 123 amostras de fezes equinas foram processadas segundo descrição feita por Lazzari et al. (1997).

\section{Análise estatística}

Para a análise estatística foi utilizado o programa SAS (Statistical Analysis System) versão 6,8 de 1992. Neste programa os dados foram submetidos a análise de variância e, quando houve diferença significativa, as médias dos tratamentos foram comparadas pelo teste de Tukey em um nível de significância de 5\%. Realizou-se também o teste do qui-quadrado $(\mathrm{P}<0,05 \%)$ e análise de correlação (Pearson). Este último foi aplicado entre o percentual de isolamento e o percentual de animais soropositivos de cada haras.

\section{RESULTADOS}

Ao testar o "fator equi" obtido através da técnica descrita por Takai et al. (1984a) o resultado não foi considerado satisfatório. Optou-se então por utilizar o sobrenadante obtido após a segunda centrifugação descrita na técnica deste mesmo pesquisador, que demonstrou um resultado excelente no teste das placas.

Os resultados do teste sorológico foram expressos em títulos e título médio geométrico (GMT). Os percentuais de soropositivos, sem levar em consideração os títulos, estão representados no Quadro 1. A maior taxa foi encontrada no Haras $5(95,50 \%)$ e a menor no Haras $2(81,25 \%)$, não havendo porém, diferença significativa entre estes resultados.

Analisando separadamente as categorias animais (éguas e potros) observou-se que em todos os haras, com exceção do Haras 2, o percentual de soropositividade foi igual (Haras 3) ou superior (Haras 1, 4, 5 e 6) no soro sanguíneo dos potros (Quadro 1). Os animais mais jovens que apresentaram anticorpos neutralizantes contra o "fator equi", possuiam 2 e 9 dias de vida. Os demais soropositivos tinham entre 1 e 5 meses de idade.

Quadro 1. Percentual de soropositividade dos haras as diferentes categorias animais ao teste de inibição da hemólise sinérgica

\begin{tabular}{|c|c|c|c|c|c|c|c|}
\hline \multirow[t]{2}{*}{ Haras } & \multicolumn{3}{|c|}{ Potros } & \multicolumn{3}{|c|}{ Éguas } & \multirow{2}{*}{$\begin{array}{c}\text { Total } \\
\%\end{array}$} \\
\hline & $\mathrm{N}^{\mathrm{O}}$ & Pos. & $\%$ & $\mathrm{~N}^{\mathrm{o}}$ & Pos. & $\%$ & \\
\hline 1 & 29 & 26 & 89,65 & 52 & 42 & 80,76 & 83,95 \\
\hline 2 & 07 & 05 & 71,42 & 09 & 08 & 88,80 & 81,25 \\
\hline 3 & 16 & 14 & 87,50 & 32 & 28 & 87,50 & 87,50 \\
\hline 4 & 31 & 31 & 100,00 & 35 & 28 & 80,00 & 89,40 \\
\hline 5 & 08 & 08 & 100,00 & 14 & 13 & 92,85 & 95,50 \\
\hline 6 & 23 & 23 & 100,00 & 34 & 29 & 85,29 & 91,23 \\
\hline Total & 114 & 107 & 93,85 & 176 & 148 & 84,09 & 87,93 \\
\hline
\end{tabular}

No Haras 1, 88\% (22/25) das éguas com anticorpos neutralizantes para o $R$. equi possuiam seus potros soropositivos, da mesma forma no Haras $271,42 \%$ (5/7), Haras $386,66 \%(13 / 15)$, Haras $488,46 \%(23 / 26)$, Haras 5 e $6100 \%(8 /$ 8 e 20/20 respectivamente). Um percentual de 7,92\% (8/101) de potros, filhos de éguas soropositivas, não apresentaram estes anticorpos específicos. Estes dados se referem à parcela de éguas soropositivas (101) que possuiam o soro dos respectivos potros amostrados. 
O título máximo detectado em cada propriedade foi de 1:4 nos Haras 1 e 3; 1:8 no Haras 5; 1:128 nos Haras 2 e 6 e 1:256 no Haras 4. Através do teste de Tukey ficou demonstrado que o título 1:2 foi o mais encontrado. Transformando estes dados em títulos médios geométricos (GMT), encontrou-se o maior GMT no Haras $2(3,60)$ e o menor no Haras 3 $(1,73)$. A análise das categorias animais revelou um GMT significativamente mais elevado nos potros, com uma variação de 5,03 no Haras 6 a 2,20 no Haras 1. No soro sangüíneo das éguas encontrou-se uma variação no título médio geométrico de 3,08 no Haras 2 a 1,17 no Haras 1 (Fig. 1).

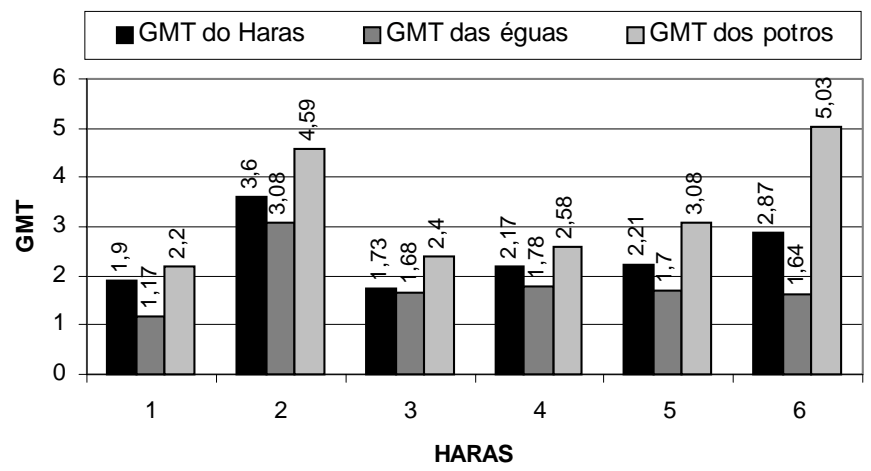

Fig. 1. Título médio geométrico (GMT) de anticorpos contra $R$. equi no soro sanguíneo de éguas e potros analisados pelo teste de inibição da hemólise sinérgica.

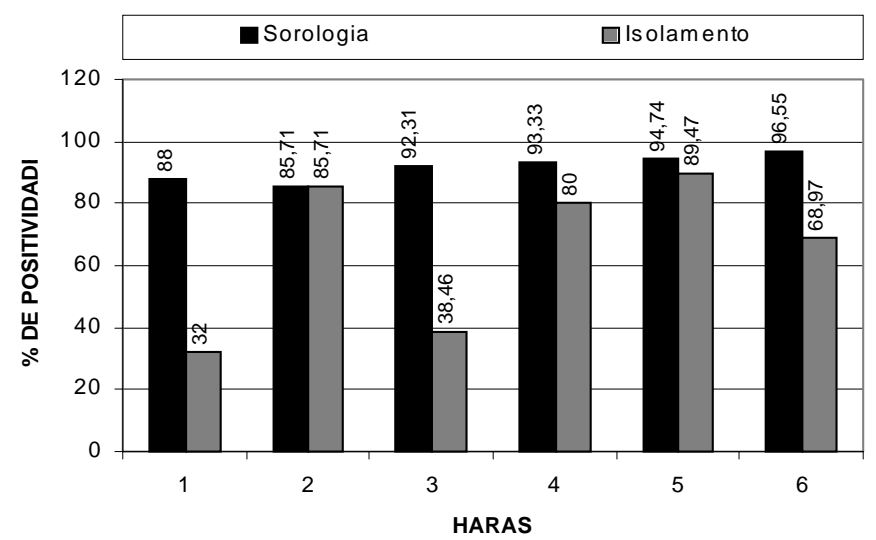

Fig. 2. Percentuais de soropositividade dos equinos a $R$. equi pelo teste de inibição da hemólise sinérgica e respectivas taxas de isolamento do mesmo agente nas fezes dos animais.

Dentro de cada haras, coletou-se um percentual de amostras de fezes dos animais que tiveram o soro sanguíneo amostrado. Analisando o resultado destas amostras (123), encontrou-se correlação $(\mathrm{P}<0,0473)$ entre o isolamento de $R$. equi nas fezes e a soropositividade dos animais. Um percentual de $62,60 \%(77 / 123)$ das amostras foram positivas para o isolamento do $R$. equi nas fezes e para os anticorpos neutralizantes no soro sanguíneo, 30\% (37/123) foram soropositivas, porém sem isolamento do agente nas fezes. De apenas $2,40 \%(3 / 123)$ das amostras coletadas foi isolado o agente das fezes sem detectar anticorpos específicos no soro e $4,80 \%$ (6/123) foram negativos tanto para o isolamento quanto para a detecção de anticorpos. A observação individual de cada haras revelou que a maior correlação entre animais soropositivos e o achado da bactéria nas fezes ocorreu no Haras 2, onde, todos os animais com anticorpos contra $R$. equi eliminavam este agente pelas fezes. A menor correlação foi observada no Haras 1 , onde, em somente 36,36\% (8/22) dos animais soropositivos foi isolado a bactéria das fezes. Os demais percentuais de soropositivos e de isolamento da bactéria podem ser observados na Figura 2.

\section{DISCUSSÃO}

$O$ resultado da sorologia demonstrou uma alta prevalência de anticorpos contra $R$. equi em todos os haras. Das 290 amostras de soro sanguíneo analisadas pela IHS, 255 foram positivas $(87,93 \%)$, demonstrando a disseminação deste agente entre a população estudada (Quadro 1). Estes animais amostrados não apresentavam evidências clínicas de qualquer uma das formas de doença causada por $R$. equi. Portanto, este dado discorda de Prescott et al. (1984a), que sugerem que a detecção de anticorpos para o "fator equi" através da IHS pode ser usada no diagnóstico de pneumonia por $R$. equi. $\mathrm{O}$ alto percentual encontrado neste trabalho, associado a normalidade clínica dos animais e o isolamento do agente nas fezes, sugere uma estimulação antigênica para produção de anticorpos neutralizantes contra o "fator equi" a partir do agente que transita pelo trato intestinal dos éguas e que se multiplica no trato intestinal de potros (Takai et al. apud Sanada et al. 1992). Gaskin et al. (1990) não concordam com esta sugestão, afirmando que estas exoenzimas não conseguem ultrapassar a barreira intestinal para induzir uma resposta imunológica. Para estes pesquisadores seriam necessários focos ativos de infecção, como uma linfadenite mesentérica ou então quadros pneumônicos. Entretanto, é pouco provável, apesar de não se ter pesquisado, que $87,93 \%$ destes animais possuíssem os focos ativos acima citados para desenvolver uma resposta imune. Analisando o Quadro 1, percebe-se que no Haras de número 2 , classificado como de ocorrência endêmica e com casos recentes registrados, ocorreu o menor percentual de positividade que foi de $81,25 \%$, sendo ultrapassado inclusive pelos Haras $3(87,5 \%)$ e $5(95,5 \%)$ que nunca tiveram problemas aparentes com esta bactéria. Esta diferença, no entanto, não foi significativa. Woolcock et al. (1987) constataram em seu trabalho, que animais pertencentes a propriedades com registros desta enfermidade, possuiam títulos muito maiores ao "fator equi" quando comparados com propriedades sem problema. Apesar do menor percentual de soropositividade ser encontrado justamente no Haras 2, o maior título médio geométrico de anticorpos foi detectado nesta propriedade, confirmando a constatação do pesquisador acima citado (Fig. 1). Talvez a incidência da enfermidade encontrada no Haras 2 esteja associada, conforme sugestão de Prescott (1991), a uma combinação de fatores como declínio de anticorpos derivados do leite materno, ausência de um mecanismo imune celular competente e a 
presença ou não de isolados virulentos do $R$. equi no ambiente. Além do exposto acima, a amostragem de soro sanguíneo coletado neste Haras foi pequena, o que pode ter, de certa forma, influenciado o resultado.

Foi encontrado um total de 93,85\% (107/114) de potros soropositivos e $84,09 \%$ (148/176) de éguas positivas (Quadro 1). Finger (1996) detectou também um maior percentual de soropositividade nos potros $(39,1 \%)$ do que em éguas $(14,6 \%)$, através do teste de IDGA. No único potro amostrado com 2 dias de vida, foi detectado anticorpos neutralizantes para o "fator equi", demonstrando provavelmente transferência passiva de imunidade, já que sua mãe era soropositiva. Dois animais com 9 dias de idade também apresentaram estes anticorpos, porém fica a dúvida se estes foram adquiridos passivamente ou produzidos ativamente, pois, segundo Gaskin et al. (1990), os potros soroconvertem para R. equi 7 dias após uma exposição experimental ao agente. Um pequeno percentual de potros, filhos de éguas soropositivas foram soronegativos $(7,92 \%)$. Vários fatores poderiam levar a isto, entre eles, a ausência ou títulos muito baixos de anticorpos específicos no colostro destas éguas, a ingestão de quantidades inadequadas do colostro, ou, em caso de imunidade não passiva, a falta de exposição ao agente etiológico, imunossupressão ou infecção recente.

O título máximo de anticorpos contra o "fator equi" encontrado em cada haras foi bastante baixo. Os maiores títulos foram encontrados nos Haras 2 e 6 (1:128) e no Haras 4 (1:256). Porém, o título encontrado com maior frequência em todos os haras foi 1:2. O maior título médio geométrico (GMT) foi detectado no Haras 2 (com ocorrência endêmica) e o menor no Haras 3, onde nunca houve registro de enfermidade por esta bactéria (Fig. 1). O GMT dos potros foi significativamente mais elevado que das éguas. Talvez, este fato possa ser explicado pela maior exposição destes animais a este agente, devido ao hábito coprofágico (Takai et al. 1987). Skalka \& Svastová (1984/85) encontraram em potros pertencentes a haras com história de infecção, através de um teste de neutralização do "fator equi" (EFN-Equi Factor Neutralization Test), um título máximo de 1:8 em animais com até 1 mês de idade, 1:256 até 2 meses, 1:512 de 2 a 4 meses de vida e 1:32 em potros entre 6 e 12 meses.

Analisando estatisticamente os resultados, encontrou-se correlação entre o isolamento de $R$. equi nas fezes e a soropositividade dos animais. A maior correlação ocorreu no Haras 2 , onde $100 \%$ dos soropositivos eliminavam $R$. equi pelas fezes. A estimulação do sistema imune para produção de anticorpos neutralizantes do "fator equi" pode ser realizada tanto pela infecção do trato respiratório como por uma infecção do trato intestinal (Prescott 1991). Isto poderia explicar os $30 \%$ de animais soropositivos, citado nos resultados, mas sem a bactéria nas fezes. Outra explicação é a provável eliminação intermitente da bactéria nas fezes. Quanto aos animais com isolamento, mas soronegativos, vários fatores poderiam justificar tal resultado, como: infecção recente do trato intestinal; animal imunossuprimido, sem condições de armar uma resposta humoral ou a incapacidade do teste detectar baixos títulos de anticorpos (Gaskin et al. 1990). Finger (1996) encontrou um percentual bastante inferior de animais com isolamento e sorologia positiva $(34,38 \%$ e e $65,63 \%$ de isolamento positivo com sorologia negativa. Por se tratar de um dado soroepidemiológico devemos considerar que as regiões estudadas contribuíram para estas diferenças, mas principalmente $o$ teste utilizado, que no caso de Finger foi a imunodifusão em gel de ágar.

\section{CONCLUSÕES}

- O título médio geométrico de anticorpos é mais elevado na propriedade com casos clínicos recentes de enfermidade causada por $R$. equi.

- A alta prevalência de anticorpos em animais aparentemente sadios sugere não haver relação entre sorologia e doença. Assim sendo, existe a necessidade de estabelecer a possível relação entre títulos de anticorpos e a sua importância na deteç̧ão da enfermidade.

- A soropositividade dos equinos ao teste de inibição da hemólise sinérgica apresenta correlação com o isolamento de $R$. equi nas fezes dos respectivos animais.

- O título médio geométrico de anticorpos contra R. equi encontrado nos potros é mais elevado que nas éguas.

\section{REFERÊNCIAS}

Becu T. 1994. Rhodococcus equi: Diagnostico serologico e immunoprofilaxis; experiencias clinicas y de laboratorio en la República Argentina. I Congr. Equine Medicine, São Paulo, SP. (Abstract)

Bisping W. \& Amtsberg G. 1988. Colour Atlas for the Diagnosis of Bacterial Pathogens in Animals. Paul Parey Scientific Publishers, Berlin. 339p.

Carter G.R. \& Cole J.R. 1990. Diagnostic Procedures in Veterinary Bacteriology and Mycology. 5th ed. Academic Press, San Diego. 620p.

Ellenberger M.A., Kaeberle M.L. \& Roth J.A. 1984. Equine humoral immune response to Rhodococcus (Corynebacterium) equi. Am. J. Vet. Res. 45(11): 24282430.

Finger G.P. 1996. Caracterização de amostras de Rhodococcus equi de eqüinos no Rio Grande do Sul. Tese de Mestrado, Curso de Pós-Graduação em Medicina Veterinária, UFRGS, Porto Alegre. 98 p.

Gaskin J.M., Brewer B. \& Koterba A. 1990. Diagnostic significance of serological responses to Rhodococcus equi in horses. 8th ACVIM Forum, Washington. (Abstract)

Hillidge C.J. 1986. Review of Corynebacterium (Rhodococcus) equi lung abscesses in foals: Pathogenesis, diagnosis and treatment. Vet. Rec. 119: 261-264.

Lazzari A., Vargas A.C., Weiss L.H.N. \& Borges C.H. 1996. Rhodococcus equi: sorologia e avaliação da tranferência passiva de anticorpos para potros. Ciência Rural, Santa Maria, 26(2): 251-255.

Lazzari A., Vargas A.C., Dutra V., Costa M.M. \& Flores L.A.S. 1997. Aspectos epidemiológicos do Rhodococcus equi em equinos do município de Bagé, RS, Brasil. Ciência Rural, Santa Maria, 27(3):441-446.

Madigan J.E., Hietala S. \& Muller J. 1991. Protection against naturally adcquired Rhodococcus equi pneumonia in foals by administration of hyperimmune plasma. J. Reprod. Fertil. 44 (Suppl.):571-578.

Nakazawa M. 1980. Detection of colt serum antibody against Corynebacterium equi by agar gel diffusion. Jap. J. Vet. Sci. 42:551-555.

Nakazawa M. Isayama Y. \& Kashiwazaki M. 1987. Diagnosis of Rhodococcus equi infection in foals by the agar gel diffusion test with protein antigen. Vet. Microbiol. 15:105-113.

Prescott J.F., Lastra M. \& Barksdale L. 1982. Equi factors in the identification of Corynebaterium equi Magnusson. J. Clin. Microbiol. 16(5):988-990. 
Prescott J.F., Coshan-Gauthier R. \& Barksdale L. 1984a. Antibody to equi factor(s) in the diagnosis of Corynebacterium equi pneumonia of foals. Can. J. Comp. Med. 48:370-373.

Prescott J.F. 1987. Epidemiology of Rhodococcus equi infection in horses. Vet. Microbiol. 14:211-214.

Prescott J.F. 1991. Rhodococcus equi: An animal and human pathogen. Clin. Microbiol. Rev. 4(1):20-34

Prescott J.F. \& Hoffman A.M. 1993. Rhodococcus equi. Veterinary Clinics of North America: Equine Practice 9(2):375-384.

Quinn P.J., Carter M.E., Markey B. \& Carter G.R. 1994. Clinical Veterinary Microbiology. Wolfe, London. 648p.

Sanada Y., Noda H. \& Nagahata H. 1992. Serological survey of Rhodococcus equi infection in horses in Hakkaido. J. Vet. Med. Sci. 54(4):649-652.

Skalka B. \& Svastová A. 1984/85. Two techniques for detection of antibodies against Corynebacterium (Rhodococcus) equi in horse sera. Vet. Microbiol. 10:293-300.

Skalka B. 1987. Dynamics of equi factor antibodies in sera of foals kept on farms with differing histories of Rhodococcus equi pneumonia. Vet. Microbiol. 14(3):269-276.

Sweeney C.R. \& Wilkins P.A. 1992. Respiratory diseases in foals: Diagnostic tools for the equine practitioners approaching a herd problem. 38th Annual Convention of the American Association of Equine Practitioners, Davis. (Abstract)

Takai S., Fujimori T., Katsuzaki K. \& Tsubaki S. 1987. Ecology of Rhodococcus equi in horses and their environment on horse-breeding farms. Vet. Microbiol. 14:233-239.

Takai S. Kazama N. \& Tsubaki S. 1990. Radial immunodiffusion enzyme assay for detection of antibody to Rhodococcus equi in horse sera. Japn. J. Vet. Sci. 52(3):653-655.

Takai S., Anzai T., Yamaguchi K., Kakizaki S., Takahagi J., Sato Y., Takehara F., Tamada Y., Matsukura S., Tani A., Kato M., Seno N., Sasaki Y. Tsubaki S. \& Kamada M. 1994a. Prevalence of virulence plasmids in environmental isolates of Rhodococcus equi from horse-breeding farms in Hokkaido. J. Equine Sci. 5(1):21-25.

Takai S., Sasaki Y. \& Tsubaki S. 1995. Rhodococcus equi infection in foals - Current concepts and implication for future research. J. Equine Sci. 6(4):105-119.

Woolcock J.B., Mutimer M.D., Bowles P.M. 1987. The immunological response of foals to Rhodococcus equi: A review. Vet. Microbiol. 14:215-224.

Yager J.A. 1987. The pathogenesis of Rhodococcus equi pneumonia in foals. Vet. Microbiol. 14:225-232. 